\title{
FUNÇÃO DOCENTE NO ENSINO SUPERIOR: DISCUSSÃO PARCIAL PARA UMA PROPOSTA DE FORMAÇÃO CONTINUADA DE DOCENTES UNIVERSITÁRIOS ${ }^{1}$
}

\author{
Carlos Nazareno Ferreira Borges \\ Universidade Federal do Espírito Santo, Vitória, Espírito Santo, Brasil \\ Antônio Fernandes da Cruz Junior \\ Universidade Federal do Espírito Santo, Vitória, Espírito Santo, Brasil \\ Sandra Soares Della Fonte \\ Universidade Federal do Espírito Santo, Vitória, Espírito Santo, Brasil
}

\begin{abstract}
Resumo
Em 2007 foi realizada uma experiência piloto no Centro de Educação Física e Desportos da Universidade Federal do Espírito Santo, denominada de Projeto Vem com a Gente (VCG). A iniciativa foi de desenvolver um projeto de formação continuada com professores substitutos da casa, enquanto tentativa de pensar um projeto de formação continuada coletiva para docentes do ensino superior. O presente texto trata da análise e interpretação de uma das categorias, retirada de um estudo maior realizado sobre o projeto VCG: a função docente no ensino superior. Os resultados da discussão apontam para uma convergência entre os objetivos do projeto e os pressupostos para formação continuada, indicando boas pistas para iniciativas futuras.
\end{abstract}

Palavras-chave: Função Docente. Formação Continuada. Ensino Superior.

\section{Introdução}

$\mathrm{O}$

presente texto é parte das análises que foram realizadas a partir de um estudo que se desenvolveu durante a experiência de uma proposta de formação continuada ${ }^{2}$ efetivada com os professores substitutos $^{3}$ do Centro de Educação Física e Desportos (CEFD) da Univer-

1-O presente trabalho não contou com apoio financeiro de nenhuma natureza para sua realização e não apresenta conflito de interesses.

2-Ainda que apresente pequenas diferenças conceituais, como afirma Gunther e Molina Neto (2005), este termo também poderá ser entendido como formação contínua e formação permanente.

3-Considera-se professor substituto aquele professor contratado por tempo determinado, mediante contrato de locação de serviços, exclusivamente para ministrar au- 
sidade Federal do Espírito Santo (UFES) no ano de $2007^{4}$, por meio de uma iniciativa denominada de Projeto "Vem Com a Gente" (VCG). $\mathrm{O}$ estudo realizado se constituiu como estratégia de monitoramento do projeto, no sentido de potencializar o alcance dos objetivos do mesmo, voltados para a qualificação da ação docente dos professores no ensino superior, bem como contribuir para sua formação, uma vez que tendo uma situação funcional temporária, entendia-se aquela etapa de suas vidas como um momento ainda forte de formação.

Mas, o estudo realizado durante o projeto VCG teve a intenção também de investigar se os pressupostos do projeto e as atividades desenvolvidas no mesmo apresentavam potencialidades de construir discursos e práticas imediatas que apontassem para futuras possibilidades de transposição didática de conteúdos discutidos em um processo de formação continuada para a prática docente dos sujeitos envolvidos.

No itinerário metodológico do estudo, optou-se inicialmente por fazer a coleta dos dados através de observação participante que, segundo as orientações de Gil (1999), apresenta-se como o método recomendado para se obter informações referentes aos comportamentos, atitudes, e manifestações verbais dos indivíduos. Nesse sentido, muitas informações foram registradas em um diário de campo. No entan-

las em curso de graduação, à vista do plano de trabalho departamental, condicionado à existência de vaga. Tal exigência dar-se-á em função da falta de docente decorrente de: exoneração ou demissão; falecimento; aposentadoria; licença gestante; licença para tratamento de saúde; licença por motivo de doença em pessoa da família; licença por motivo de afastamento do cônjuge; licença para atividade política; licença para desempenho de mandato classista; licença para capacitação; afastamento para exercício de mandato eletivo; vacância para posse em outro cargo inacumulável; afastamento para cursar pós-graduação no exterior (UFES. Resolução $n^{0}$ 03/98. Conselho de Ensino, Pesquisa e Extensão. Disponível em <www.daocs.ufes.br>. Acesso em 24 abr. 2007).

4-O Projeto Vem Com a Gente, que deu origem a esse estudo, iniciou-se em 2007 e se constituiu em um piloto para o processo de formação continuada para professores substitutos, ampliando-se para professores efetivos. A partir da experiência original se constituiu um grupo de estudo e uma linha de pesquisa no Programa de Pós Graduação em Educação Física da UFES, resultando em uma dissertação de mestrado com a temática de formação continuada de docentes do ensino superior. Portanto, outros trabalhos surgirão em publicações posteriores a partir daquela experiência original.

Pensar a Prática, Goiânia, v. 15, n. 2, p. 272-550, abr./jun. 2012 
to, após duas reuniões de trabalho, viu-se que o grupo de professores substitutos do projeto VCG poderia se constituir em um grupo focal. A partir desse momento, optou-se por uma técnica mista de coleta de dados e, então, os procedimentos foram desenvolvidos por dois pesquisadores.

$\mathrm{Na}$ perspectiva de estratégia mista mencionada, enquanto um dos pesquisadores continuava com a estratégia de observação participante, outro pesquisador conduzia a discussão com o grupo focal e, dessa forma, além das anotações no diário de campo, lançou-se mão das verbalizações gravadas e posteriormente transcritas, constituindo-se como atas de reunião. Portanto, o produto transcrito dos encontros ${ }^{5}$ se constituiu em documentos, caracterizando também a utilização do método de análise documental sobre o material ${ }^{6}$ (GIL, 1999). O modelo de análise dos dados foi o de análise de conteúdo, proposto por Sourioux e Lerat (2002), o qual orienta a organização e interpretação dos dados através de categorias analíticas.

Nesse texto, temos como objetivo discutir uma das categorias resultantes da análise do material da pesquisa - a função docente no ensino superior. Um dos focos de trabalho do VCG era o de discutir as características dessa função docente no ensino superior e de como se constrói um processo de excelência ${ }^{7}$ para a mesma. No contexto do estudo maior realizado sobre o VCG e acompanhando a questão mais

5-Os registros de cada encontro do VCG, sob a forma de atas, foram realizados ora pelo monitor e ora pelo coordenador do Projeto. Após a sua elaboração, eram disponibilizados a todos os integrantes do VCG para possíveis alterações.

6-O VCG previu como instrumentos de acompanhamento a utilização de questionários fechados. Entretanto, a coleta dos dados por meio de questionários não ocorreu devido à falta de disponibilidade dos integrantes do Grupo. Desse modo, o VCG substituiu tal método por entrevistas semi-estruturadas. Assim, os dados obtidos pelas transcrições das falas nas reuniões deram origem à Síntese de Avaliação (DOCUMENTOS DE SÍNTESE DOS TRABALHOS DO VCG, 2007), que por sua vez, consistiu em coletar, através das falas de cada participante do Projeto, impressões acerca dos avanços, dos limites e das proposições apontadas pelo Grupo em relação aos trabalhos desenvolvidos pelo VCG no primeiro semestre de sua implementação (2007/01).

7-Conforme poder-se-á observar em diferentes argumentos nesse texto, considerase excelência da função docente no ensino superior, a articulação harmônica e eficaz da formação no tripé ensino-pesquisa-extensão.

Pensar a Prática, Goiânia, v. 15, n. 2, p. 272-550, abr./jun. 2012 
ampla já mencionada, no momento questionamos então se os discursos e práticas imediatas dos professores substitutos participantes do projeto VCG relacionados com a categoria função docente, indicam futuras possibilidades de transposição didática dos conteúdos discutidos no processo de trabalho para a prática docente dos sujeitos envolvidos.

$\mathrm{Na}$ busca de respostas para a questão levantada, utilizaremos da análise realizada em nosso estudo, que usou dos dados constituídos pelas verbalizações e pelos documentos produzidos nos encontros do VCG, confrontando com o quadro teórico de base tanto dos encontros quanto do estudo.

O quadro teórico pressupôs um referencial pautado em saberes fundamentais à prática educativo-crítica/progressista defendida por Paulo Freire, que julgamos ser conteúdos fundamentais aos processos de formação inicial e de formação continuada de professores. Além disso, foi utilizado um amplo leque de autores para discutir as categorias de análise dos dados do estudo, porém, nesse texto trazemos somente as contribuições de Pimenta; Anastasiou (2002), abordando a formação continuada; Chamlian (2003), discutindo a função docente na educação superior; Taffarel (2001), refletindo a função docente nas Instituições de Ensino Superior (IES) Públicas.

Dito isso, apresentaremos brevemente os pressupostos do VCG, no sentido de situar o contexto. Em seguida, faremos a discussão sobre a categoria elencada - função docente no ensino superior; e, enfim, faremos considerações pertinentes ao nosso entendimento de como os pressupostos desenvolvidos no VCG e aqui apresentados, podem colaborar na direção da qualificação da formação de docentes.

\section{Caminhando com o VCG}

O VCG foi uma experiência como projeto de extensão do CEFD/UFES que buscou oferecer uma proposta de formação continuada aos seus dez professores substitutos ${ }^{8}$. Isto porque o VCG entendeu

8-Segundo as chefias dos departamentos do CEFD, o Centro, no segundo semestre de 2007, possuía trinta e cinco professores. Dezesseis eram do Departamento de Desportos (DD) e dezenove do Departamento de Ginástica (DG). No DD, quatorze eram efetivos, e dois substitutos. Já no DG, onze são efetivos, e oito substitutos. Entretanto, dos vinte e cinco professores efetivos do CEFD, cinco estavam em pro- 
que esse período de atuação docente se constitui em mais uma etapa de formação desses professores.

Essa proposta de trabalho consistiu no estabelecimento de um fórum permanente aos professores substitutos denominado de Grupo de Estudos dos Substitutos (GESU), que funcionou, metodologicamente, com seminários de estudo e discussão durante os períodos do calendário letivo (semestres) do ano de 2007. Tais seminários não possuíram o caráter de "aula", e sim fóruns de discussão acerca de temáticas que nortearam reflexões no âmbito das práticas pedagógicas dos professores. Foram realizadas sete reuniões no primeiro semestre de 2007 e cinco reuniões no segundo semestre. Cada reunião apresentou aproximadamente duas horas de duração e, nos encontros do GESU, foram sugeridos textos ${ }^{9}$ que pudessem ser norteadores das discussões.

No tocante às temáticas levantadas nas reuniões, observamos que $o$ GESU discutiu desde os "pontos falhos" do próprio Projeto VCG até questões relevantes à prática docente do Ensino Superior. Nessa última, foram abordadas questões sobre a função docente no ensino superior nas instituições públicas e privadas; o papel da formação continuada; a pesquisa; a orientação acadêmica; a cultura docente; e as estratégias para a formação continuada através do trabalho colaborativo. Todas essas questões se transformaram em categorias analíticas do estudo desenvolvido.

Dentre as discussões realizadas e do produto documental das mesmas, resultantes nas categorias de análise, passamos a abordar especificamente sobre a função docente.

\section{Função docente no ensino superior}

Para discutir a função docente no ensino superior, fazemos tentativas de entender os perfis dos professores do ensino superior público e privado, os aspectos institucionais peculiares entre as IES públicas e

cesso de afastamento/licença/cedido (dois professores do DD e três do DG) dos cursos de graduação do CEFD. Já os professores substitutos estavam em diferentes estágios de formação. Assim, dos dez substitutos, sete eram mestres, sendo que três doutorandos. Já os outros três professores, dois cursavam o mestrado e um possuía especialização (lato sensu).

9-Os textos norteadores das discussões do GESU/VCG foram sugeridos tanto pelos professores condutores das temáticas como pelos professores substitutos.

Pensar a Prática, Goiânia, v. 15, n. 2, p. 272-550, abr./jun. 2012 
privadas, e a formação continuada que parecem ser concebidas nestas IES. Tais discussões foram provocadas devido à existência de muitas reflexões geradas entre os professores do GESU a respeito de quais características, habilidades, competências e inclinações, seriam necessárias para o desenvolvimento da ação docente (DOCUMENTOS DE SÍNTESE DOS TRABALHOS DO VCG, 2007) ${ }^{10}$.

Referente ao perfil do professor do ensino superior público, chegou-se a um consenso de que esse profissional seria o docente comprometido com uma atuação competente e direcionada pelo tripé de excelência da universidade: ensino, pesquisa e extensão.

Entretanto, segundo Silva (2001) existe muita discussão quanto à atuação de todos os professores das IES públicas nesse tripé ou que possuam perfil para tal. Ocorre que o próprio sistema de acesso parece favorecer a entrada do profissional com perfil definido a partir de prioridades. Atualmente, com as demandas de ampliação de vagas e cursos nas IES públicas, com direcionamento também para as pós-graduações, parece se conjugar a opção pelos adjuntos (doutores) e, desta forma, delineando a opção pela pesquisa, ou para atuação nas pós-graduações. As implicações dessa possível relação são discutidas por Moreira (2007).

No entanto, no caso específico da Educação Física, como a formação stricto sensu se delineia pela formação do pesquisador, conforme apontado por Moreira (2007), nem todos os docentes titulados possuem o perfil necessário para ingressar nas IES públicas com direcionamento ao ensino ou à extensão, e esse fato pode vir a comprometer, de certa forma, a perspectiva da produção de conhecimento a partir já dos cursos de graduação, constituinte do ensino como elemento daquele tripé universitário.

Conforme foi discutido e encontramos nos registros de reuniões do GESU,

[...] a formação dos professores de nível superior não é uma formação "regularizada", pois os cursos de mestrado e de doutorado não se prestam a preparar o "professor", e sim o "pesquisador". Logo, nem todos que prestam concursos possuem o perfil mais completo para trabalhar em instituição pública

10-Síntese da reunião de 16/05/2007.

Pensar a Prática, Goiânia, v. 15, n. 2, p. 272-550, abr./jun. 2012 


\section{(DOCUMENTOS DE SÍNTESE DOS TRABALHOS DO VCG, 2007) ${ }^{11}$.}

Essa afirmativa é corroborada por Chamlian (2003) nos esclarecendo que, com a reforma universitária de 1968, foi estabelecido como principio norteador para o desenvolvimento da universidade brasileira, a indissociabilidade entre ensino e pesquisa. Assim, a autora comenta que

"Argumentava-se, então, que tais cursos teriam como objetivo a formação do professorado competente para atender à expansão do ensino superior, assegurando, ao mesmo tempo, a elevação dos níveis de qualidade" (p.04), e ainda que "[...] este princípio, formal e obrigatório, acabou por transformar todos os professores universitários em professores pesquisadores" (p. 44).

Entretanto, salientamos que, por mais que os cursos de pós-graduação tenham assumido a função da formação do docente do nível superior, e mais precisamente da formação do "professor pesquisador", não encontramos dados claros quanto à atuação de docentes deste nível, pertencentes às IES públicas, envolvidos com a pesquisa e extensão. Pelo contrário, temos evidência, do caso específico da instituição em que o presente estudo foi desenvolvido, da presença de docentes doutorados trabalhando somente com o ensino, por não possuir produção acadêmica exigida para ingresso nos quadros de pós-graduação. Não parece estranho que os docentes dessa instituição, que tendo sido preparados para a pesquisa, nela não consigam logo entrar em nível de excelência, mas permaneçam no ensino, para o qual não foram treinados?

Talvez seja exagerada a afirmativa quanto ao não treinamento para o ensino, afinal, no contexto da expansão do sistema de ensino superior e na tarefa de gestão e controle desse sistema por parte do governo federal, existe em muitos programas de pós-graduação a disciplina Metodologia do Ensino Superior, como fomento para a formação pedagógica. Contudo, concordamos com Chamlian (2003) ao afirmar que uma disciplina voltada para a formação pedagógica estrita dificilmente daria conta de preencher a variedade de necessidades que cada curso e que cada professor possam apresentar.

11-Síntese da reunião de 16/05/2007.

Pensar a Prática, Goiânia, v. 15, n. 2, p. 272-550, abr./jun. 2012 
Pimenta e Anastasiou (2002) contribuem com a discussão acima, quando ao descrever a gênese da didática dizem que é possível identificar a influência de alguns mitos sobre o seu campo de estudos e suas possibilidades na formação de professores. De acordo com as autoras, no caso da docência universitária, um desses mitos relaciona-se ao resumir a formação do docente universitário a uma única disciplina pedagógica. Nesse caso, considera-se a Pedagogia, Teoria da Educação, Didática, Teoria do Ensino, entre outras, apenas como um corpo de conhecimentos técnicos instrumentais, capaz de apresentar receitas às diversas situações de ensino.

Dessa forma, seguindo Pimenta e Anastasiou (2002), questionamos: seria possível formar pedagogicamente, em uma ou poucas disciplinas, o docente universitário com um rol de conhecimentos que instrumentalizam a prática do ensino, já que esse é entendido como prática social, um fenômeno complexo, realizado por seres humanos com seres humanos, modificado pela ação e relação dos sujeitos (professores e estudantes) situados historicamente, e que por sua vez, são modificados nesse processo? No nosso ponto de vista a resposta a essa indagação é potencialmente negativa.

Dialogando com Chamlian (2003), é possível entender que a simples introdução de uma disciplina de caráter pedagógico, sem ter claros os pressupostos da atividade universitária, no contexto específico em que se atua, e no que deveria consistir a prática, significaria reduzir as possibilidades de reflexão sobre a natureza dessa atividade no ensino superior. Há também o risco de acontecer algo semelhante ao que ocorre nas licenciaturas, onde se trata a formação pedagógica como "um receituário rapidamente adquirido e que pouca influência produz na formação em nível de pós-graduação" (CHAMLIAN, 2003, p. 62). Ainda segundo a autora, uma alternativa para essa situação é desenvolver trabalhos de formação que "congregasse professores mais experientes e iniciantes" (p.63), algo similar ao que o VCG estava propondo no desenvolvimento de seu trabalho.

No que diz respeito ao perfil dos professores das IES privadas, este parece estar mais relacionado ao envolvimento quase exclusivo ao ensino (salvo poucas exceções, de instituições privadas que investem em pesquisa e extensão). Nesses casos, os aspectos institucionais são fortes condicionantes das funções docentes, ou seja, nas IES privadas os professores são contratados na forma de "horista" (contrato por hora de trabalho), e esse regime de trabalho acaba priorizando o ensino, ho- 
ra/aula em sala. Nesse sentido, surgiu a seguinte questão na reunião do GESU: seria possível a dinâmica da formação continuada estudando sua própria prática, numa Instituição de Ensino Superior Privada?

Ocorre que, em muitos casos, devido à falta de incentivos, torna-se mais difícil a participação do docente das IES particulares ao fomento da pesquisa, extensão e até mesmo dos programas de formação continuada, embora isso seja cobrado enquanto iniciativa individual e parcialmente oferecida pelas IES sob a forma de eventos esporádicos.

Questões gerais passaram a ser levantadas: O que queremos como docentes? A docência é um "ganha pão" ou idealismo, possibilidade de transformar a sociedade? O que norteia a opção dos indivíduos pela carreira numa instituição pública? Seria possível superar a ideia de que a causa fosse a estabilidade, a aposentadoria e o status?

$\mathrm{Na}$ opinião do professor/coordenador do Projeto $\mathrm{VCG}^{12}$, pertencer ao serviço público é uma opção, baseada no perfil para se trabalhar com extensão e/ou pesquisa (essa última de forma mais frequente), isto é, uma preocupação com construção de conhecimento que extrapole a dimensão do ensino, ou da sala de aula, uma vez que essa acontece também em IES particulares. A partir desse perfil, os argumentos acerca da estabilidade, da aposentadoria integral e do status são frágeis como motivadores da opção por aderir e manter-se no serviço público. A opção se configura em produzir conhecimento numa articulação entre ensino, pesquisa e extensão. Isso porque o docente, segundo o professor/coordenador do VCG, seria o mediador de um processo de construção do conhecimento, cuja responsabilidade é "[...] dividida por três grupos: é de responsabilidade da Instituição, do docente e do discente [...], portanto, não cabe um professor somente transmissor de conhecimento, o qual não interessa nem à educação básica, a qual há muito tempo vem tentando romper com esse modelo". (DOCUMENTOS DE SÍNTESE DOS TRABALHOS DO VCG, 2007) ${ }^{13}$.

Nesta perspectiva, houve um consenso de que as IES públicas poderiam ser espaços profícuos em favorecer o desenvolvimento do perfil do professor preocupado com a construção do conhecimento sob a perspectiva do tripé universitário, como princípio organizador do tra-

12-DOCUMENTOS DE SÍNTESE DOS TRABALHOS DO VCG (2007). Síntese da reunião de 30/05/2007.

13-Síntese da reunião de 30/05/2007.

Pensar a Prática, Goiânia, v. 15, n. 2, p. 272-550, abr./jun. 2012 
balho pedagógico e identificador da universidade que visa a melhor qualificação profissional (TAFFAREL, 2001)

Em relação à esperada qualificação mencionada, Bosi e Reis (2004) destacam que a formação de professores deve compreender todas as atividades como parte de um todo do trabalho docente. Por isso que quando se fala em formação se difere de qualificação, esta última de interesse do mercado. Os autores dizem ainda que a experiência cotidiana e prática se constituem em uma dimensão importante desse amplo processo chamado de formação.

Ocorre que por uma série de dificuldades políticas internas nas IES públicas, esse fomento, muitas vezes, é comprometido. Talvez, a questão vá para além do individuo isoladamente, envolve a articulação (política) a ser realizada dentro das IES.

Nos documentos do VCG vimos que "Essa discussão (acerca da função docente) nos impele a lançar um olhar avaliativo sobre nosso quadro docente. Nesse caso, será preciso também discutir possibilidade de propor um trabalho articulado de discussão sobre a prática pedagógica dos professores" (DOCUMENTOS DE SÍNTESE DOS TRABALHOS DO VCG, 2007) ${ }^{14}$.

Parece que ambas as propostas apresentadas se constituem em boas iniciativas à formação de docentes universitários. Quando falamos aqui em trabalho docente, não só nos referimos à prática pedagógica no âmbito do ensino, pesquisa e extensão, mas também nas relações e decisões políticas junto às IES. Assim, acreditamos que o processo de formação continuada, dependendo de como for concebido, possa proporcionar ao professor reflexões também no viés político, através de uma postura autônoma, crítica e reflexiva.

Ao analisar o documento da "Conferência Internacional sobre o Ensino Superior - uma perspectiva docente, Paris, 1997", promovida pela Organização Sindical Internacional da Educação, Pimenta e Anastasiou (2002) comentam que nesse evento surgiram preocupações sobre temas do campo educacional que até então eram ausentes na docência universitária. Entre os temas estavam: a qualidade da educação; a educação à distância e as novas tecnologias; a gestão e controle do ensino superior; o financiamento do ensino e da pesquisa; o mercado de trabalho e a sociedade; a autonomia e as responsabilidades das ins-

14-Síntese da reunião de 16/05/2007.

15-Síntese da reunião de 16/05/2007.

Pensar a Prática, Goiânia, v. 15, n. 2, p. 272-550, abr./jun. 2012 
tituições; os direitos e liberdades dos professores do ensino superior; as condições de trabalho.

As autoras afirmam que o domínio das questões mencionadas acima tem se configurado como requisito necessário ao exercício da docência no ensino superior, uma vez que se espera o envolvimento desses profissionais na administração e gestão nos segmentos das IES, tomando decisões acerca dos currículos, políticas de pesquisa e de financiamento; não apenas no âmbito das IES, mas também nos âmbitos dos demais sistemas públicos e das instituições científicas de fomento, de políticas de pesquisa, de ensino e de avaliação.

Entendemos que tais discussões têm demonstrado não só a preocupação para a formação no âmbito técnico, mas também no âmbito político da formação dos docentes de nível superior. Tais discussões são extremamente interessantes ao professor substituto, visto que se parte do pressuposto que esses docentes possuem pretensões em construir carreira no ensino superior nas IES públicas. Em continuidade, dizemos que a importância atinge a todos os docentes universitários.

Por outro lado, Freire (2006) nos faz entender que a prática educativa, por si só, não pode ser neutra, alheia a decisões políticas, pois essa prática:

[...] demanda a existência de sujeitos, um que, ensinando, aprende, outro que, aprendendo, ensina, daí o seu cunho gnosiológico; a existência de objetos, conteúdos a serem ensinados e aprendidos; envolve o uso de métodos, de técnicas, de materiais; implica, em função de seu caráter diretivo, objetivo, sonhos, utopias, ideais. Daí a sua politicidade, qualidade que tem a prática educativa de ser política, de não poder ser neutra (FREIRE, 2006, p. 69-70).

Desse modo, percebemos que a atuação do professor em sua prática pedagógica necessariamente exige dele uma definição política baseada em sua visão de mundo, que norteará sua ação docente. Assim, Freire (2006) diz que a prática docente não pode ser reduzida apenas ao ensino dos conteúdos (entendido como formação técnica). Na realidade, segundo o autor, o ensino dos conteúdos é entendido como:

[...] um momento apenas de minha atividade pedagógica. Tão importante quanto ele, o ensino dos conteúdos, é o meu teste- 
munho ético ao ensiná-los. É a decência com que o faço. É a preparação científica revelada sem arrogância, pelo contrário, com humildade. É o respeito jamais negado ao educando, a seu saber de experiência feito que busco superar com ele. Tão importante quanto o ensino dos conteúdos é a minha coerência entre o que digo, o que escrevo e o que faço (p.103).

Daí a necessidade de se pensar para além de uma formação puramente pedagógica ou técnica, também uma formação política no contexto de uma proposta de formação mais ampla, tanto inicial quanto continuada.

Já em relação às IES públicas e privadas, podemos notar que estas instituições, caracterizam-se em dois espaços distintos, com especificidades e particularidades próprias, constituindo importantes condicionantes da função docente. Entretanto, não podemos esquecer que independentemente da instituição de ensino, a prática docente pressupõe um conjunto de saberes que tendem a nortear a atuação do professor, seja qual for sua opção política ou visão de mundo.

Nesse sentido, dialogamos com Freire (2006), ao discutir sobre alguns saberes fundamentais à prática "educativo-crítica" ou "progressista" da formação docente. Segundo o autor, é preciso, sobretudo, que o formando, desde o principio de seu processo de formação, assumindo-se como sujeito também da produção do saber, convença-se de que ensinar não é transferir conhecimento, mas criar as possibilidades para a sua produção ou sua construção. Caso contrário, resultará na formação do "falso sujeito". É preciso que, desde o início do processo de formação, fique claro que "[...] quem forma se forma e re-forma ao formar e quem é formado forma-se e forma ao ser formado" (FREIRE, 2006, p. 23). É nesse sentido, que de acordo com o autor, ensinar não é transferir conhecimentos.

O educador não pode se negar ao dever, na sua prática pedagógica, de reforçar/estimular a capacidade crítica e criadora dos "educandos". Essa perspectiva, apontada por Freire, leva-nos a pensar a função docente nas diferentes IES. $O$ fato do professor não atuar em uma IES pública não seria impedimento para o não comprometimento com a produção do conhecimento, por mais que as políticas das instituições não incentivassem o trabalho perspectivado no tripé universitário ensino, pesquisa e extensão. 
Mesmo que sua atuação se restrinja exclusivamente ao ensino, caberia ao docente não perspectivar sua ação pedagógica sob a ótica da "transferência do conhecimento", e sim em uma ação que proporcionasse ao educando e a ele mesmo (docente), (re) construções do saber.

A nosso ver, a pesquisa pode ser encarada como um ponto fundamental nesse processo, ou seja, o ato de se implementar no ensino elementos da pesquisa, com o intuito de estimular problematizações e investigações de um dado objeto/situação/fenômeno, contribuiria de forma significativa com a produção do conhecimento por parte dos sujeitos (professores e estudantes). Mas isso foi assunto que ficou para outra categoria analítica e, portanto, em trabalho posterior.

\section{Considerações finais}

A partir das discussões levantadas referentes à categoria de análise função docente no ensino superior, podemos considerar que os resultados encontrados, sob a luz dos referenciais teóricos do presente estudo, revelam que as construções de discurso dos professores substitutos possuem indicadores de convergência com os pressupostos orientadores de formação continuada propostos pelo VCG.

Acreditamos que esse fato seja significante, pois abre possibilidades de uma transposição destes pressupostos, do plano das ideias (discurso) à prática docente, de forma a contemplar uma possível construção de uma proposta de formação continuada aos grupos de professores do ensino superior. Entretanto, não queremos afirmar a ideia de que a prática só se constrói mediante a teoria. Entendemos que a prática se (re)constrói de forma simultânea aos discursos. A transposição aconteceria no "caminho", à medida que os sujeitos dialogassem suas ações do cotidiano com suas construções de discursos e (re)descobrissem elementos com os quais se identificam. Possivelmente tais elementos podem vir a se fazer presentes de forma latente no cotidiano e, portanto podem passar a se constituir tanto em discurso quanto em prática (res)significada.

Segundo Orlandi (2001, p. 15), o discurso "[...] torna possível tanto a permanência e a continuidade quanto o deslocamento e a transformação do homem e da realidade em que ele vive". Dialogando com esse autor, Fernandes (2005) diz que é preciso transcender o âmbito da linguística para outros espaços, para que os discursos possam ser entendidos, isto é, para descobrir o que está entre a língua e a fala. Diz 
ainda que, dessa forma, o discurso se materializa e se transforma em práticas daquele que discursa e é então que a linguagem constrói história.

Como vemos, parece haver então uma espécie de "simbiose" entre aquilo que está no campo do discurso, com aquilo que se manifesta nas ações, e talvez por isso, "[...] constatando, nos tornamos capazes de intervir na realidade, tarefa incomparavelmente mais complexa e geradora de novos saberes do que simplesmente a de nos adaptar a ela" (FREIRE, 2006, p. 77).

Assim, queremos dizer que o fato do GESU apresentar convergência com os pressupostos de formação continuada do VCG abre "possibilidades", e não estamos afirmando que realmente irá acontecer, de "transposição" para construção de uma proposta de formação continuada aos grupos de professores do ensino superior.

Essa lógica nos remete ao pressuposto da ética, "entre aquilo que falo e aquilo que faço". Em relação àqueles que "falam uma coisa e fazem outra", Freire (2006, p. 34) diz que "Não há pensar certo fora de uma prática testemunhal que o re-diz em lugar de desdizê-lo". Se realmente irá ocorrer "transposição", cabe a futuros estudos investigar.

Role of teachers in higher education: discussion for a partial motion for continuing education of college teachers

\begin{abstract}
In 2007 a pilot experiment was performed at the Center for Physical Education and Sports, Federal University of Espirito Santo, called Project Come with Us (VCG). The initiative was to develop a project of continuing education with substitute teachers from home, while trying to think a project of continuing education conference for teachers in higher education. This paper deals with the analysis and interpretation one of the categories, taken from a larger study conducted on the project VCG: teaching in higher education. The results of the discussion points to a convergence between the objectives of the project and the requirements for continuing education, indicating good insights into future initiatives.
\end{abstract}

Keywords: Function Teaching. Continuing Education. Higher Education.

Papel de los docentes em educación superior: discusión de propuestas parcial de formación continua de los docentes universitarios

\title{
Resumen
}

En el año 2007 una experiencia piloto se realizó en el Centro de Educación Física y Deportes de la Universidad Federal de Espírito Santo, llamado Proyecto Ven con 
nosotros (VCG). La iniciativa para desarrollar un proyecto de educación continua con los maestros sustitutos de la casa mientras trataba de pensar en el proyecto de la conferencia de educación continua para maestros en la educación superior. Este artículo trata sobre el análisis e interpretación de las categorías, tomadas de un estudio más amplio sobre el proyecto llevado a cabo VCG: la enseñanza en la educación superior. Los resultados de los puntos de discusión para una convergencia entre el objetivo del proyecto y los requisitos para continuar la educación, la indicación buenas ideas en iniciativas futuras.

Palabras clave: Enseñanza de Funciones. La Educación Permanente. La Educación Superior.

\section{Referências}

BOSI, A. P.; REIS, L. F. A reforma universitária nas universidades federais do Paraná. Universidade e Sociedade. Brasília, ano XIV, n 34 out., 2004.

CARNEIRO, E. A.; CARNEIRO, E. C. A. R. O discurso e o interdiscurso. Disponível em: <http://mail.google.com/mail/?attid $=0.1 \&$ disp $=$ vah\&view $=$ att $\&$ th $=1168 \mathrm{c} 235 \mathrm{df} 6124 \mathrm{~b} 4>$. Acesso em: $02 \mathrm{dez} .2007$

CHAMLIAN, H. C. Docência da universidade: professores inovadores na USP. Cadernos de Pesquisa, n. 118, março 2003. Disponível em <http://www.scielo.br/pdf/cp/n118/16829.pdf >. Acesso em: 03 out. 2007

DOCUMENTOS DE SÍNTESE DOS TRABALHOS DO VCG. Sínteses das reuniões ocorridas nos dois semestres de 2007. Vitória: UFES, 2007. (Mimeo).

FERNANDES, C. Análise do discurso: reflexões introdutórias. Goiânia: Trilhas Urbanas: 2005.

FREIRE, P. Pedagogia da autonomia. 34. ed. São Paulo: Paz e Terra, 2006.

GIL, A. C. Métodos e téenicas de pesquisa social. 5. ed. São Paulo: Atlas, 1999.

GUNTHER, M. C. C.; MOLINA NETO, V. Formação Permanente de Professores: algumas considerações acerca das concepções do professorado de Educação Física. In: FIGUEIREDO, Z. C. C. (Org.). For- 
mação profissional em educação física e o mundo do trabalho. Coletânea de Textos Volume 01 Ano 2005. Grupo de Trabalho Temático/CBCE Formação Profissional - Campo de Trabalho. Vitória: Gráfica da Faculdade Salesiana, 2005. p. 209-235.

MOREIRA. E. C. Contribuições dos programas de pos-graduação stricto sensu na formação e atuação dos docentes de ensino superior: $\mathrm{O}$ Caso da Educação Física. Tese de Doutorado. Faculdade de Educação Física - Universidade Estadual de Campinas/SP, 2007.

ORLANDI, E. P. Análise de discurso: princípios e procedimentos. 3 ed. Campinas, SP: Pontes, 2001.

PIMENTA, S. G.; ANASTASIOU, L. G. C. Docência no ensino superior. Coleção Docência em Formação. São Paulo: Cortez, 2002. v. I.

SILVA, A. C. Alguns problemas do nosso ensino superior. Estudos Avançados 15 (42), 2001. Disponível em <http://www.scielo.br/pdf/ea/v15n42/v15n42a14.pdf.> Acesso em 24 abr. 2007.

SOURIOUX, J. L.; LERAT, P. Análise de texto: método geral e aplicação no direito. São Paulo: Martins Fontes, 2002.

TAFFAREL, Celi Nelza Zulke. Formação profissional e diretrizes curriculares: do arranhão à Grangrena. Universidade e Sociedade. Brasília, ano.XI, n. 25, p. 107-119. Dez. 2001.

UFES. Conselho de Ensino, Pesquisa e Extensão. Resolução n $\mathbf{n}^{\mathbf{0}}$ 03/98. Estabelece normas para processo seletivo de contratação de professor substituto. Texto disponibilizado em 21 jan. 1998. Disponível em: $<$ www.daocs.ufes.br/index.asp?pagina $=$ Novo_Estatuto_UFES $>$. Acesso em: 24 abr. 2007.

VENTORIM, S. et al.. Práticas pedagógicas e lógica meritocrática no ensino superior: o debate na revista Universidade e Sociedade. In: SOUZA E SILVA, J; BARBOSA, J. L.; SOUSA, A. I.(Orgs.). Práticas pedagógicas e lógica meritória na universidade. Rio de Janeiro: UFRJ, 2006.

Recebido em: 06/04/2011

Revisado em: 15/05/2011

Aprovado em: 29/06/2011

Pensar a Prática, Goiânia, v. 15, n. 2, p. 272-550, abr./jun. 2012 


\section{Endereço para correspondência}

carlosnazareno@ufv.br

Carlos Nazareno Ferreira Borges

Universidade Federal do Espírito Santo

Centro de Educação Física e Desportos.

Av. Fernando Ferrari, 514,

Campus Goiabeiras

29075-910 - Vitoria, ES - Brasil 